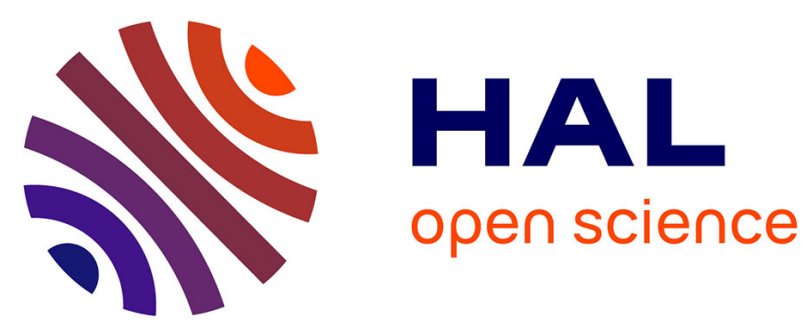

\title{
Comparative study of solvolysis of technical lignins in flow reactor
}

Woldemichael Sebhat, Ayman El-Roz, Agnès Crepet, Catherine Ladaviere, Denilson da Silva Perez, Stéphane Mangematin, Cédric Cabral Almada, Lea Vilcocq, Laurent Djakovitch, P. Fongarland

\section{To cite this version:}

Woldemichael Sebhat, Ayman El-Roz, Agnès Crepet, Catherine Ladaviere, Denilson da Silva Perez, et al.. Comparative study of solvolysis of technical lignins in flow reactor. Biomass Conversion and Biorefinery, 2019, 10 (2), pp.351-366. 10.1007/s13399-019-00435-z . hal-03031346

\section{HAL Id: hal-03031346 https://hal.science/hal-03031346}

Submitted on 15 Nov 2021

HAL is a multi-disciplinary open access archive for the deposit and dissemination of scientific research documents, whether they are published or not. The documents may come from teaching and research institutions in France or abroad, or from public or private research centers.
L'archive ouverte pluridisciplinaire HAL, est destinée au dépôt et à la diffusion de documents scientifiques de niveau recherche, publiés ou non, émanant des établissements d'enseignement et de recherche français ou étrangers, des laboratoires publics ou privés. 


\title{
Comparative study of solvolysis of technical lignins in flow reactor
}

\author{
Woldemichael Sebhat ${ }^{1} \cdot$ Ayman El-Roz $^{1} \cdot{\text { Agnès } \text { Crepet }^{2} \cdot \text { Catherine Ladavière }^{2} \text { - Denilson Da Silva Perez }}^{3}$. \\ Stéphane Mangematin ${ }^{1}$. Cédric Cabral Almada ${ }^{1} \cdot$ Léa Vilcocq $^{4} \cdot$ Laurent Djakovitch $^{1}$ (D) $\cdot$ Pascal Fongarland $^{1,4}$
}

Received: 6 February 2019 / Revised: 3 May 2019 / Accepted: 5 May 2019

(C) Springer-Verlag GmbH Germany, part of Springer Nature 2019

\begin{abstract}
The solvolysis of technical lignins was evaluated using water/ethanol solvent mixture with the aim of producing monomeric aromatic compounds in a continuous flow bench reactor. Four lignins issued from various biomasses (softwood, wheat straw) and extracted using different pulping processes (kraft, soda, organosolv) were engaged in the study. Before being converted, these lignins (two kraft, a soda, and an organosolv) were characterized by a multitechnique approach coupling compositional analysis, NMR, IR, GC, and SEC. Data thus obtained allowed us to point out the main differences in terms of structure and chemical composition. Based on its high solubility in water and water/ethanol mixture, alkaline lignin (i.e., from the kraft process) was used to optimize the reaction parameters. Thus, we found out that working at $225^{\circ} \mathrm{C}$ under $8 \mathrm{MPa}$ nitrogen using a 1 -wt $\%$ basic solution of lignin allowed to operate the reactor without difficulties (no foam formation, no char) when a $1 / 1$ water/ethanol mixture was used. Under these conditions, alkaline lignin was converted up to $76 \%$. Other lignins were then evaluated leading to conversions between 46 and 74\%. The reaction mixture obtained was fractioned to PM (precipitated matter), OP (organic products), and AP (aqueous phase soluble products) to allow careful analyses of the products. Analytical data obtained showed particularly that the number of $\beta-\mathrm{O}-4$ linkages in the remaining solid material (PM) decreases significantly (up to - 95\%) that correlated with the formation of monomeric organic compounds in OP, however in low amount due to over reactions leading to compounds evolving in the aqueous phase. Generally, whatever the lignin, guaiacol is the main aromatic compound observed under all reaction conditions evaluated.
\end{abstract}

Keywords Kraft lignin $\cdot$ Organosolv lignin $\cdot$ Alcoholysis $\cdot$ Multitechnique characterization $\cdot$ Flow reactor

\section{Introduction}

Electronic supplementary material The online version of this article (https://doi.org/10.1007/s13399-019-00435-z) contains supplementary material, which is available to authorized users.

Laurent Djakovitch

laurent.djakovitch@ircelyon.univ-lyon1.fr

1 Université de Lyon, Université Claude Bernard Lyon 1, CNRS, IRCELYON, UMR 5256, 2 avenue Albert Einstein, 69626 Villeurbanne, France

2 Université de Lyon, Ingénierie des Matériaux Polymères, UMR 5223, CNRS, Université Claude Bernard Lyon 1, 15 Boulevard Latarjet, 69626 Villeurbanne, France

3 FCBA / Pôle Nouveaux Matériaux, Domaine Universitaire, CS 90251, 38044 Grenoble Cedex, France

4 Laboratoire de Génie des Procédés Catalytiques, UMR 5285, CNRS, CPE, Université Claude Bernard Lyon 1, 43, bd du 11 novembre 1918, B.P. 82077, 69616 Villeurbanne Cedex, France
In order to decrease our dependency on fossil resources, biobased resources can be a promising route for an alternative economy. However, the transition from a well-established petro-based to biomass-based economy will require intensive research. In recent years, the public awareness for more environmentally friendly products increased. Stimulated by policy makers and other economic aspects, the use of renewable feedstocks by the chemical industry can thus only increase. To meet these needs, lignocellulosic biomass can be an interesting feedstock [1].

Lignocellulosic biomass is mainly composed of three biopolymers, namely, cellulose as a polymer of glucose units linked with $\beta-1 \rightarrow 4$-glycosidic bonds, hemicellulose resulting from polymerization of C5 and C6 sugar units, and lignin, a biopolymer made of aromatic units linked through different $\mathrm{C}-\mathrm{C}, \mathrm{C}-\mathrm{O}$, and $\mathrm{C}-\mathrm{O}-\mathrm{C}$ linkages [2].

The lignin biopolymer is a complex matrix composed of three monomers called monolignols. Coniferyl alcohol 
(guaiacyl), sinapyl alcohol (syringyl), and $p$-coumaryl alcohol ( $p$-hydroxyphenyl) are the three building blocks and the composition of lignins can vary depending on the biomass; even within a tree variation in composition can be observed [3]. Ether bonds (i.e., $\mathrm{C}-\mathrm{O}$ bonds) and carbon-carbon (i.e., $\mathrm{C}-\mathrm{C}$ ) bonds are the most prevailing type of linkages between lignin monomers. Evidently, the ether bonds are the easiest to cleave and the $\mathrm{C}-\mathrm{C}$ are the hardest ones [4]. In addition, the complex nature of lignin isolation steps can greatly modify the properties and the structure of native lignin and not always as benefit of lignin valorization [5].

Native lignin, i.e., lignin as a biopolymer present in lignocellulose, is well described in the literature. It can undergo several treatments to give technical lignins, as for example the kraft lignin produced in the kraft process. The structure of technical lignins is different from native lignin: ether bonds are less present, $\mathrm{C}-\mathrm{C}$ bonds between aromatic moieties are created by recondensation reactions, heteroatoms like sulfur are introduced, etc. Despite several improvements in the knowledge of the structure of technical lignins, their exact chemical structure is today still not fully resolved making necessary the use of different complementary analytical techniques whose results should be carefully considered in the absence of standardization of analytical protocols [6].

Even though 50 million tons of technical lignin are processed by the paper industry, only 100,000 tons of kraft lignin is diverted for other applications than energy use [7]. Valueadding applications for lignin are limited to few examples probably due to recondensation/repolymerization reactions and the presence of minerals that make such upgrading difficult. To the best of our knowledge, among all types of produced lignins, the Borregaard's lignosulfonates of the vanillin process is one of the commercially successful lignin upgrading process.

Organosolv processes for lignin extraction were developed as environmentally alternatives to the kraft process [8-10]. Organosolv lignins contain generally lower residual minerals and carbohydrates, but due to elevated temperatures and pressures, lignins present generally highly modified structures compared to that of native lignin [11, 12]. Nevertheless, in these processes, alcohols were proven to be good solvents to fraction lignocellulosic materials to produce pulp [13]. Next to preventing partial recondensation reaction through their $\mathrm{H}$ donor properties, alcohols, or alcohol/water mixtures, can readily help to cleave ether bonds present in lignin. Despite the limited role of ethanol on $\mathrm{C}-\mathrm{C}$ bond cleavage, since ether bonds in lignin represent ca. $80 \%$ of the intermolecular linkages, it is reasonable to expect an effect of the use of alcohol in lignin depolymerization [14]. Inspired by these results, in recent years, pure ethanol and water/ethanol systems under suband supercritical conditions were used to produce aromatics from lignin [15-17]. Beyond the economic factors that make ethanol an interesting co-solvent, it also presents interesting features for application in lignin valorization. The free radical scavenging property can limit the condensation reactions which counter the depolymerization step [18]. Another advantage of ethanol is it can act as a nucleophile reagent for ether cleavages [19]. Finally, the rather facile recovery of ethanol by simple evaporation step will lower operation costs.

An alternative approach to the use of alcohols as co-solvent, or other capping agents, to prevent recondensation was based on a continuous-mode operation reported by Hulteberg et al. [20]. They demonstrated that treating Indulin kraft lignin in continuous flow reactor in the presence of sodium hydroxide at $240{ }^{\circ} \mathrm{C}$ led to the formation of monomeric and oligomeric products. Millireactors were used in two studies [21, 22] for the basic depolymerization of kraft lignin. In both cases, the application of short residence times had a favorable impact on monomeric compounds. To the best of our knowledge, the conversion of lignin in a fixed reactor using a mixture of ethanol and water was never studied.

Several works related to lignin upgrading have been reported in the literature and reviewed [23-29]; however, there is still a need for processes valorizing technical lignins in an economically viable way. Such lignins are recalcitrant materials that usually yield a lot of chars as final product.

The hydrothermal conversion of lignins in basic aqueous and alcoholic media was recently reviewed by Otromke et al. [30]. The reaction usually takes place between 200 and $350{ }^{\circ} \mathrm{C}$ and leads to the cleavage of ether bonds at low temperature. Monomeric and oligomeric compounds are usually isolated and analyzed.

In this paper, we studied the solvolysis of several technical lignins in a water/ethanol mixture in a flow reactor in mild conditions associated to fractionation process of the reaction mixture in order to recover separately the monomeric aromatic compounds from the oligomeric products and residual nonliquefied lignin fraction. Operating conditions were designed in a green engineering perspective: mild temperature, cheap and nontoxic solvents, and no char production. Implementation of biorefinery processes, such as lignin transformation, in continuous reactors is important for the design of intensified processes. This work aims to demonstrate the feasibility of technical lignin valorization in mild conditions in flow reactor.

\section{Materials and methods}

\subsection{Starting materials}

Ethanol (Carlo-Erba 99\%), $\mathrm{K}_{2} \mathrm{CO}_{3}$ (Sigma-Aldrich), $\mathrm{KHCO}_{3}$ (Carl Roth 99\%), KOH (Chimie Plus 85\%), HCl (SigmaAldrich 37\%), acetone (Merck chemicals 99.8\%), and all chemicals were used as received without further purification. Silicon carbide was used to fill the reactor (VWR, grain size $1.65 \mathrm{~mm})$. 
Four technical lignins were selected for the study. It was decided to focus on lignins representative of industrial processes, i.e., kraft and organosolv processes.

Kraft lignin from spruce (hereinafter alkaline lignin) with low sulfate content was obtained from Sigma-Aldrich France, Protobind 1000 soda lignin type was isolated from wheat straw, and Sarkanda grass was obtained from Green Value SA Switzerland.

Another kraft lignin was produced starting from a black liquor (maritime pine) from the paper industry (40\% wt $\%$ dry matter). The highly alkaline black liquor was first neutralized with $\mathrm{CO}_{2}$ by bubbling to precipitate lignin. After centrifugation, the recovered solid has a purity of $60 \%$. It was further washed with a 2-wt $\% \mathrm{H}_{2} \mathrm{SO}_{4}$ solution followed by centrifugation. After three washing and drying cycles, a purity of 92\% was achieved (from Klason + acid-soluble lignin following TAPPI T22 om-02 and TAPPI UM 250 measured immediately after preparation).

An organosolv lignin was produced from wheat straw by extraction using a mixture of formic acid and acetic acid following the CIMV process. The liquor used was a mixture of acetic acid/formic acid/water in 60/20/20 ratio, at $100{ }^{\circ} \mathrm{C}$. After evaporation of the organic acids from black liquor, the lignin was recovered by precipitation by adding water.

These lignins were analyzed by complementary techniques. Associated data can be found in Tables 1, 2, and 3.

\subsection{Reactor}

Experiments were carried out in a trickle-bed reactor setup manufactured by Vinci Technologies operating between 150 and $275^{\circ} \mathrm{C}$. The reactor was a stainless-steel tube of $60 \mathrm{~mL}$ filled with $\mathrm{SiC}$ (carborundum). Initial lignin solution contained $1 \mathrm{wt} \%$ lignin and, when added, $0.1 \mathrm{wt} \%$ base. After complete dissolution of components, the mixture was fed to a liquid reserve of $3 \mathrm{~L}$ from where a diaphragm metering pump delivered the liquid at the top of the reactor at $20 \mathrm{~mL} \mathrm{~h}^{-1}$. Nitrogen gas was delivered at $12 \mathrm{MPa}$ on the setup; a pressure relief valve was used to adjust to $10 \mathrm{MPa}$ and a mass flow controller (Brooks $5850 \mathrm{TR}$ ) assured a constant $10 \mathrm{NL} \mathrm{h}^{-1}$ flow. Gas and liquid were mixed at the top of the bed and trickle down co-currently. Effluent leaving the bed was cooled with a small tubular heat exchanger and entered a high pressure gas-liquid separator. A back-pressure regulator ensured an 8-MPa pressure in the apparatus and discharged the excess gas; for the liquid, a level regulator coupled with control valve (Kammer) ensured a constant liquid level. The flowsheet of the setup can be found in the ESI. Two pressure transmitters (Keller PR33 and converter K-104) were installed upstream and downstream of the reactor to monitor the pressure drop in the reactor.

\subsection{Product fractionation}

To ensure careful analyses of the reaction mixtures, they were fractioned into three phases (more details in the ESI). An aliquot of $50 \mathrm{~mL}$ was sampled and $10 \% \mathrm{HCl}$ solution was added until $\mathrm{pH} 1$ (checked with a $\mathrm{pH}$ indicator). The resulting solution was mixed for about 2 min that produced a color change from dark brown to light brown due to residual lignin precipitation. After centrifugation at $4000 \mathrm{rpm}$ for $10 \mathrm{~min}$, the solid was separated from the supernatant and dried under vacuum for $6 \mathrm{~h}$. It was weighed to give an estimation of precipitated matter (hereinafter PM). The liquid phase was extracted thrice with $50 \mathrm{~mL}$ dichloromethane, and both organic and aqueous fractions were then concentrated separately on a rotary evaporator and dried under reduced pressure. After weighing, the organic phase (OP) was then diluted in acetonitrile before analysis. The aqueous part (AP) was redissolved in THF; it contained water-soluble lignin fragments. The residual salts from upstream processes (kraft, soda, etc.), $\mathrm{Cl}$ from hydrochloric acid used for precipitation, and the residual base when added are not solubilized in THF and could be therefore separated. Fractionation protocol was repeated two or three times from the same reaction mixture to assure reproducibility of the experimental procedure. The experimental error margin was found to be $<6 \%$ for OP fraction, $<3 \%$ for AP fraction, and $<0.6 \%$ for PM fraction.

\subsection{Analytical techniques}

\subsubsection{Klason lignin}

The standard procedure from NREL "Determination of structural carbohydrates and lignin in biomass" [31] was used to obtain the Klason lignin content.

Table 1 Origin of the four technical lignins

\begin{tabular}{llll}
\hline Designation & Initial biomass & Pulping method & Supplier \\
\hline (A) Alkaline lignin & Spruce & Kraft & Sigma-Aldrich \\
(B) Kraft lignin & Maritime pine & Kraft & FCBA \\
(C) Protobind 1000 & Wheat straw and Sarkanda grass & Soda & Green Value SA \\
(D) Organosolv lignin & Wheat straw & Organosolv (acetic acid/formic acid) & \\
\hline
\end{tabular}


Table 2 Chemical composition of technical lignins

\begin{tabular}{|c|c|c|c|c|c|c|c|c|c|}
\hline \multirow[t]{2}{*}{ Designation } & \multicolumn{4}{|c|}{ Elemental composition (\%) } & \multirow{2}{*}{$\begin{array}{l}\text { Water content } \\
(w t \%)\end{array}$} & \multirow{2}{*}{$\begin{array}{l}\text { Ash content } \\
(\mathrm{wt} \%)\end{array}$} & \multirow{2}{*}{$\begin{array}{l}\text { Acid-soluble } \\
\text { lignin (wt } \%)\end{array}$} & \multirow{2}{*}{$\begin{array}{l}\text { Acid-insoluble } \\
\text { lignin (wt\%) }\end{array}$} & \multirow{2}{*}{$\begin{array}{l}\text { Combined sugar } \\
\text { content (wt } \%)\end{array}$} \\
\hline & $\mathrm{C}$ & $\mathrm{H}$ & $\mathrm{O}$ & $\mathrm{S}$ & & & & & \\
\hline Alkaline lignin & 48 & 5 & 34 & 4 & 6 & 20 & 39.5 & 47.3 & 1.4 \\
\hline Kraft lignin & 62 & 5 & 29 & 4 & 3 & 2 & 3.9 & 87.0 & 1.8 \\
\hline Protobind 1000 & 62 & 6 & 30 & 1 & 2 & 4 & 13.6 & 82.7 & 2.0 \\
\hline Organosolv lignin & 60 & 6 & 32 & 0 & 2 & 3 & 4.9 & 85.4 & 3.0 \\
\hline
\end{tabular}

The standard procedure from NREL "Determination of structural carbohydrates and lignin in biomass" [31] was used to obtain the data related to acid-soluble lignin (ASL), acid-insoluble lignin (AIL), and combined sugar content (CSC). C, H, O, N, and S content measurements were obtained from elemental analysis. Water (weight loss at $105^{\circ} \mathrm{C}$ ) and ash content (residual solid at $1000{ }^{\circ} \mathrm{C}$ ) were measured by thermogravimetric analysis. For lignin containing high ratio of inorganics (i.e., alkaline and Protobind 1000 lignins), mass balance overlaps $100 \%$ due to difficulties in determining properly the Klason lignin, particularly ASL

\subsubsection{GC}

Monomers in the organic phase were analyzed on a Shimadzu 2010 GC-FID equipped with a Phenomenex Zebron ZB-5HT capillary column and on a Shimadzu GC-MS QP2010 equipped with a Supelco SLB-5MS column. Samples were dissolved in acetonitrile before analysis. Product identification was possible by comparing MS data with the NIST 2017 Mass database. Toluene was used as an internal standard. OP fraction was not solely composed of monomeric but also oligomeric molecules that were hard to vaporize and detect with a GC apparatus. $\Delta_{\text {rel }}<0.3 \%$.

\subsubsection{NMR}

Phosphorus and HSQC (heteronuclear single quantum coherence) NMR measurements were collected on a Bruker Advance III $400 \mathrm{MHz}$ with a BBFO probe. Selected samples were analyzed with the ${ }^{31} \mathrm{P}$ NMR technique to quantify the $-\mathrm{OH}$ groups, and samples were prepared using a previously reported procedure (see the ESI for details) [32, 33]. The 2D HSQC experiments were performed on PM and OP fraction samples after dilution in deuterated DMSO; details on the acquisition parameters can be found in the ESI.

Table 3 SEC analysis of technical lignins

\begin{tabular}{lll}
\hline & Mw initial lignin $(\mathrm{mol} / \mathrm{g})$ & PDI* initial lignin \\
\hline Alkaline lignin & 3519 & 1.6 \\
Kraft lignin & 1740 & 1.3 \\
Protobind 1000 & 2086 & 1.4 \\
Organosolv lignin & 3884 & 1.9 \\
\hline
\end{tabular}

*PDI polydispersity index

\subsubsection{SEC}

Size exclusion chromatography was performed to determine the molar mass of lignin samples before and after the reaction. Two columns in series were used: a PL aquagel $\mathrm{OH}$ mixed $\mathrm{M}$ and a $\mathrm{PL}$ aquagel $\mathrm{OH}$ mixed $\mathrm{H}$. The mobile phase was an aqueous solution of borate $0.05 \mathrm{M}(\mathrm{pH}=9)$, at $0.5 \mathrm{~mL} \mathrm{~min}^{-1}$ flow. The detector was a refractometer. Polystyrene sulfonate standards were used for calibration. Solid samples were dissolved in aliquots of eluent before analysis.

\subsection{Solid characterization}

\subsubsection{Elemental analysis}

$\mathrm{C}, \mathrm{H}, \mathrm{O}, \mathrm{N}$, and $\mathrm{S}$ content measurements of initial lignins were done by SCA-ISA. Oxygen was measured after pyrolysis and quantification of $\mathrm{CO}$ by a specific IR detector. Carbon, hydrogen, nitrogen, and sulfur were measured after total combustion of the sample and quantification of $\mathrm{CO}_{2}, \mathrm{H}_{2} \mathrm{O}, \mathrm{N}_{2}$, and $\mathrm{SO}_{2}$ by a thermal conductivity detector.

\subsubsection{Infrared}

FTIR measurement was performed using a Vector 22 spectrometer, and 100 scans from 400 to $4000 \mathrm{~cm}^{-1}$ were collected. Samples were prepared by mixing $2 \mathrm{mg}$ of lignin sample with $400 \mathrm{mg}$ of $\mathrm{KBr}$, and an aliquot of $200 \mathrm{mg}$ was used to prepare the pellet.

\subsubsection{Thermogravimetric measurements}

TGA was performed on TGA/DSC1 thermogravimetric analyzer from METTLER TOLEDO. The samples were analyzed as received using a heating rate of $5{ }^{\circ} \mathrm{C} / \mathrm{min}$ from 25 to $1000{ }^{\circ} \mathrm{C}$. Air was used as carrier gas. It was assumed that water content corresponds to the weight loss at $105^{\circ} \mathrm{C}$, whereas the remaining weight at the end of the procedure corresponds to ash content. 


\section{Results and discussion}

\subsection{Composition and characterization of technical lignins}

\subsubsection{Material}

Four different lignins were used in this work (more details in the ESI). Most of the studies were done using commercial alkaline lignin provided by Sigma-Aldrich. This lignin was found to be highly soluble in water, as received. It was produced from softwood and contained mainly guaiacyl $(\mathrm{G})$ and $p$-hydroxyphenyl $(\mathrm{H})$ units and was commercialized as a low sulfonate lignin, but no further information was provided except the botanic origin. The kraft lignin was prepared by FCBA starting with a black liquor from maritime pinewood and following the procedure described above. This lignin includes mainly $\mathrm{G}$ and $\mathrm{H}$ units.

Annual plants, composed of G, S (syringyl), and $\mathrm{H}$ units, were used for the preparation of the Protobind 1000 and organosolv lignin. The Protobind lignin was provided by Green Value and was obtained using the soda process $(<$ $165^{\circ} \mathrm{C}$ and $\sim 150 \mathrm{~g} \mathrm{~L}^{-1}$ of $\mathrm{NaOH}$ ). Based on the low level of ash in this lignin, it was assumed that it was precipitated from black liquor using $\mathrm{H}_{2} \mathrm{SO}_{4}$. The organosolv lignin was prepared by an organosolv process as described in Section 2.1.

\subsubsection{Chemical analyses}

Except the alkaline lignin, all the samples contained high amounts of acid-insoluble lignin (i.e., Klason lignin) and are consequently not soluble in pure water (Table 2). All lignins showed residual sugars moieties. Both kraft lignin and alkaline lignin contained sulfur since $\mathrm{Na}_{2} \mathrm{~S}$ was used for pulping. In general, all the samples present similar characteristics: low water content, low ash content, and low sugar content, except the alkaline lignin, which was very different: the ash content was high, as well as the acid-soluble lignin content. It was assumed that alkaline lignin extracted from spruce wood probably contained a lot of remaining inorganics coming from pretreatment additives.

\subsubsection{Size exclusion chromatography analyses}

The size exclusion chromatography (SEC) analysis of starting materials was useful in determining an average molar mass of lignin samples. The molecular mass varied from one sample to another without a clear correlation with the type of biomass or the kind of pretreatment applied (Table 3). Organosolv lignin has the highest molecular weight, around $3900 \mathrm{Da}$, which corresponds to more than 20 guaiacyl units per molecule. Alkaline lignin also has a high $\mathrm{Mw}(3500 \mathrm{Da})$. Protobind 1000 and kraft lignin have lower initial molecular mass, around $2000 \mathrm{Da}$. These values are in accordance with molar masses reported in the literature [22].

\subsubsection{FT-IR characterizations}

On the FT-IR spectrum of lignins (see the ESI), only a few bands can be attributed without ambiguity. Bands above $1600 \mathrm{~cm}^{-1}$, namely the $\mathrm{O}-\mathrm{H}, \mathrm{C}-\mathrm{H}$, and $\mathrm{C}=\mathrm{O}$, and $1510 \mathrm{~cm}^{-1}$ for the aromatic moieties of lignin are "pure" bands [34]. They can be used to follow the evolution of lignin transformation. Moreover, they can also be used to differentiate lignin types. When lignin originated from softwood (alkaline and kraft), the bands' intensity was higher between 1505 and $1515 \mathrm{~cm}^{-1}$ than the bands' intensity between 1600 and $1700 \mathrm{~cm}^{-1}$. For lignins from straw, the intensity was similar for those bands. It was also possible to identify the origin of lignin by the presence or absence of a band at $1118 \mathrm{~cm}^{-1}$ typical of syringyl units. Evidently, this band was absent for softwood lignins (i.e., alkaline and kraft); however, it was observed for Protobind and organosolv lignins. One can note that organosolv lignin also has a band typical for quinones around $1655-1675 \mathrm{~cm}^{-1}$. On alkaline lignin, the broad peak at $1601-1710 \mathrm{~cm}^{-1}$ was attributed to aromatic skeletal vibrations and $\mathrm{C}=\mathrm{O}$ stretching, and the peak at 1030 $1040 \mathrm{~cm}^{-1}$ was attributed to aromatic $\mathrm{C}-\mathrm{H}$ in-plane deformation, $\mathrm{C}-\mathrm{O}$ deformation in primary alcohols, and $\mathrm{C}=\mathrm{O}$ stretching. The characteristic peak for $G$ units at $1140 \mathrm{~cm}^{-1}$ was present in all samples.

\subsubsection{Liquid NMR characterizations}

${ }^{31} \mathrm{P}$ NMR can give, after careful phosphitylation following the procedure provided in Section 2.4.3, valuable information on lignin samples with a relatively short amount of time compared to ${ }^{13} \mathrm{C}$ NMR [35]. Only free hydroxyl groups were quantified; hence, oxygen molecules trapped in $\mathrm{C}-\mathrm{O}-\mathrm{C}$ or carbonyl (i.e., CHO, COOR) bonds were not be visible (Table 4). Thus, five types of free $-\mathrm{OH}$ could be quantified: aliphatic $\mathrm{OH}$, guaiacyl-OH, $p$-hydroxyphenyl-OH, carboxylic acid, and phenolic $-\mathrm{OH}$ from condensed and syringyl units that were not distinguished due to overlapping of the signals [36].

Comparison of ${ }^{31} \mathrm{P}$ NMR and elementary analysis shows that around 20-30\% oxygen atoms were involved in $\mathrm{C}-\mathrm{O}-\mathrm{C}$ and $\mathrm{C}=\mathrm{O}$ bonds. Free $-\mathrm{OH}$ functions were present in various forms, as an illustration of the diversity of chemical composition of technical lignins. - OH groups from aliphatic and condensed phenolics were majority in all samples. Alkaline lignin exhibited a remarkably high level of condensed phenolics. Kraft lignin has the highest content of $-\mathrm{OH}$ in $\mathrm{G}$ units. As noticed from FT-IR, Protobind and organosolv lignins had a relatively high content of carboxyl groups. Protobind also exhibits a high amount of condensed or syringyl units, whereas organosolv lignin contains a lot of aliphatic alcohols. 
Table $4 \quad{ }^{31} \mathrm{P}$ NMR results for technical lignins

\begin{tabular}{|c|c|c|c|c|c|}
\hline \multicolumn{2}{|l|}{ Lignin } & $\begin{array}{l}\text { Alkaline } \\
\text { lignin }\end{array}$ & $\begin{array}{l}\text { Kraft } \\
\text { lignin }\end{array}$ & $\begin{array}{l}\text { Protobind } \\
1000\end{array}$ & $\begin{array}{l}\text { Organosolv } \\
\text { lignin }\end{array}$ \\
\hline \multicolumn{2}{|l|}{ Oxygen content $(w t \%)^{\mathrm{a}}$} & 34 & 29.1 & 29.5 & 31.9 \\
\hline \multicolumn{2}{|c|}{ Oxygen content in $\mathrm{C}-\mathrm{O}-\mathrm{C}$ and $\mathrm{CHO} / \mathrm{COOR}$ bonds (wt $\%$ ) } & n.d. ${ }^{\text {b }}$ & 20.6 & 20.1 & 25.8 \\
\hline \multicolumn{2}{|c|}{ Oxygen content in $\mathrm{COOH}$ functions (wt\%) } & n.d. ${ }^{\mathrm{b}}$ & 1.0 & 2.9 & 1.6 \\
\hline \multicolumn{2}{|c|}{ Oxygen content in carboxylic hydroxides COOH (wt \%) } & n.d. ${ }^{\mathrm{b}}$ & 0.5 & 1.4 & 0.8 \\
\hline \multicolumn{2}{|c|}{ Oxygen content in $-\mathrm{OH}$ groups incl. $\mathrm{COOH}$ hydroxyls $(\mathrm{wt} . \%)^{\mathrm{c}}$} & n.d. ${ }^{\mathrm{b}}$ & 8.5 & 9.4 & 6.1 \\
\hline \multirow[t]{5}{*}{ Distribution of $-\mathrm{OH}$ groups (\%) } & $-\mathrm{OH}$ in aliphatic moieties & & 33.9 & 23.7 & 39.5 \\
\hline & $-\mathrm{OH}$ in condensed phenolic and syringyl moieties & & 26.4 & 35.6 & 21.1 \\
\hline & $-\mathrm{OH}$ in guaiacyl moieties & & 30.2 & 15.2 & 18.4 \\
\hline & $-\mathrm{OH}$ in hydroxyphenyl moieties & & 3.8 & 10.3 & 7.9 \\
\hline & $-\mathrm{OH}$ in carboxyl moieties & & 5.7 & 15.2 & 13.2 \\
\hline
\end{tabular}

\footnotetext{
${ }^{a}$ Measured from elemental analysis
}

${ }^{\mathrm{b}}$ Due to the high amount of salts in this lignin, it was necessary to preliminary "wash" it. For this, after dissolution i0n pure water, lignin was precipitated using sulfuric acid and washed several times after centrifugation. Therefore, the reported value of Klason lignin represents only a fraction that prevented to obtain quantitative data representative of the lignin really used in experiments

${ }^{\mathrm{c}}$ Calculated from ${ }^{31} \mathrm{P}$ NMR on the basic of quantitative determination using cyclohexanol as internal standard after phosphitylation of the sample (see 2.3.4 and 3.1.5)

The HSQC spectra are presented in Fig. 1 (see Figs. S1-S3 for typical HSQC spectra assignments correlated to structural fragments observed in lignins). The alkaline lignin and organosolv lignin do not have high amounts of ether linkages and are not visible $(\delta \mathrm{C} / \delta \mathrm{H}, 84.4-86.2 / 4.22-$ 4.39). The initial organosolv lignin contains acetylated fragments as discussed in Section 3.1.4, and the peak centered at 20.8/2.28 $(\delta \mathrm{C} / \delta \mathrm{H})$ corresponds to acetyl signal. In all the samples studied, the correlation signal for methoxy groups (56.3/3.7) was intense. In a regular HSQC pulse sequence, the ${ }^{1} \mathrm{JCH}$ dependence of polarization transfer is not suppressed; hence, peaks are not quantitative in the entire spectral range [37]. Semiquantitative data can be obtained using a normal HSQC experiment for ${ }^{1} \mathrm{H}_{-}{ }^{13} \mathrm{C}$ pairs in a similar chemical environment [38]. Using volume integration of the NMR spectra, a rough estimation is given on the repartition $\mathrm{G} / \mathrm{H} / \mathrm{S}$ aromatic units. In the aromatic region, the difference in composition in terms of $p$-hydroxyphenyl, guaiacyl, and syringyl $(\mathrm{H} / \mathrm{G} / \mathrm{S})$ can be clearly distinguished. The analysis confirms that alkaline lignin and kraft lignin are composed of $\mathrm{G}$ and $\mathrm{H}$ units, while Protobind and organosolv lignins contain the three $\mathrm{G} / \mathrm{S} / \mathrm{H}$ units. $p$-Coumarate signals were only present in Protobind and organosolv lignins that is expected given their botanic origin. From the same HSQC experiments, we estimated the number of interunit $\beta-\mathrm{O}-4$ linkages following the procedure reported by Sun and coworkers [39]. Data indicate that the botanic origin and the extraction process affect the content in $\beta-\mathrm{O}-4$ linkage that varies from 3.5 to 14.2 units/100 aromatic units (see Table S2; Table 5).

\subsection{Solvolysis studies on technical lignins}

\subsubsection{Initial experimental screening}

Before engaging lignins in studies related to hydrolysis/solvolysis, starting materials were submitted to the fractionation protocol depicted in Fig. S5. All lignins gave a negligible amount of products in the organic phase. However, alkaline lignin yielded an important amount of products in aqueous phase $(46 \%)$. All the other lignins gave more than $90 \%$ of solid fraction corresponding to the initial material. The proportion of precipitated matter is close to the content in Klason lignin (see Table 2).

Next, screening of the temperature conditions was realized before exploiting the trickle-bed reactor setup varying the temperature between 150 and $275{ }^{\circ} \mathrm{C}$ with a $1-w t \%$ solution of kraft lignin in a water/ethanol (50/50) mixture. Liquid flow and gas flow were fixed to $20 \mathrm{~mL} / \mathrm{h}$ and $10 \mathrm{~L} / \mathrm{min}$, respectively. In these experiments, we mainly focused on the mass balance as it indicates the loss of materials due to either evolution of products in gas phase or the formation of solid materials (i.e., char) inside the reactor. Working at $4 \mathrm{MPa}$ nitrogen between 150 and $225{ }^{\circ} \mathrm{C}$ revealed a mass loss of 10 and $17 \%$, respectively. Working at higher temperatures resulted in heavy mass loss and reactor plugin that was attributed to char formation. Therefore, working nitrogen pressure was increased to $8 \mathrm{MPa}$. Thus, under such pressure conditions, mass loss at $225{ }^{\circ} \mathrm{C}$ corresponded to that previously observed (i.e., $17 \%$ ); however; at higher temperatures $\left(250\right.$ and $\left.275{ }^{\circ} \mathrm{C}\right)$, it increased to $60-65 \%$ mainly due to the formation of char and products in the gas phase. 


\section{Alkaline}

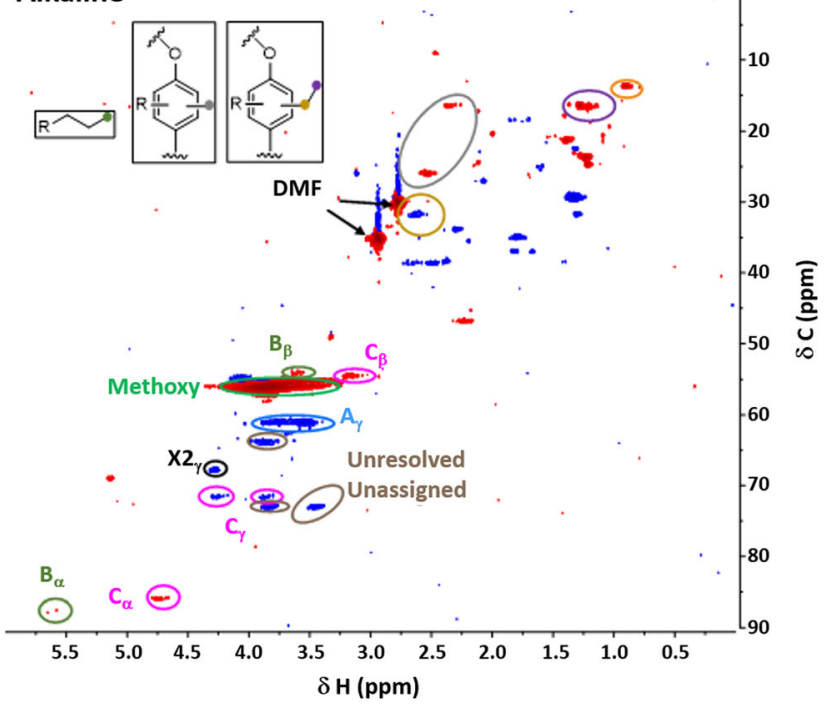

\section{Protobind}

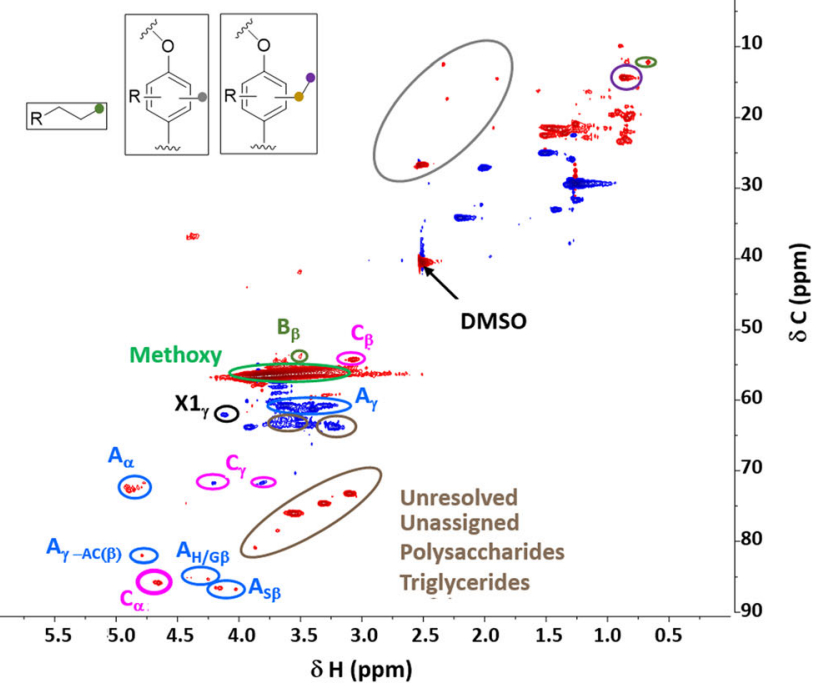

Fig. 1 Side chain region on the HSQC spectra of technical lignins

\subsubsection{Solvolysis of alkaline lignin}

Effect of water/ethanol ratio Solvolysis reaction with a mixture of water and ethanol was performed at $225{ }^{\circ} \mathrm{C}$, $8 \mathrm{MPa}$, keeping the liquid and flow conditions as before. As explained above, reaction conditions were selected to minimize the formation of char and maximize the lignin conversion characterized by the amount of products found in the organic phase after fractionation. After the test, the reaction mixture was submitted to a fractionation procedure to isolate and analyze independently the organic, aqueous, and solid fractions (Fig. S5).

Alkaline lignin was chosen as a reference because of its high solubility in all solvent mixtures. Five experiments
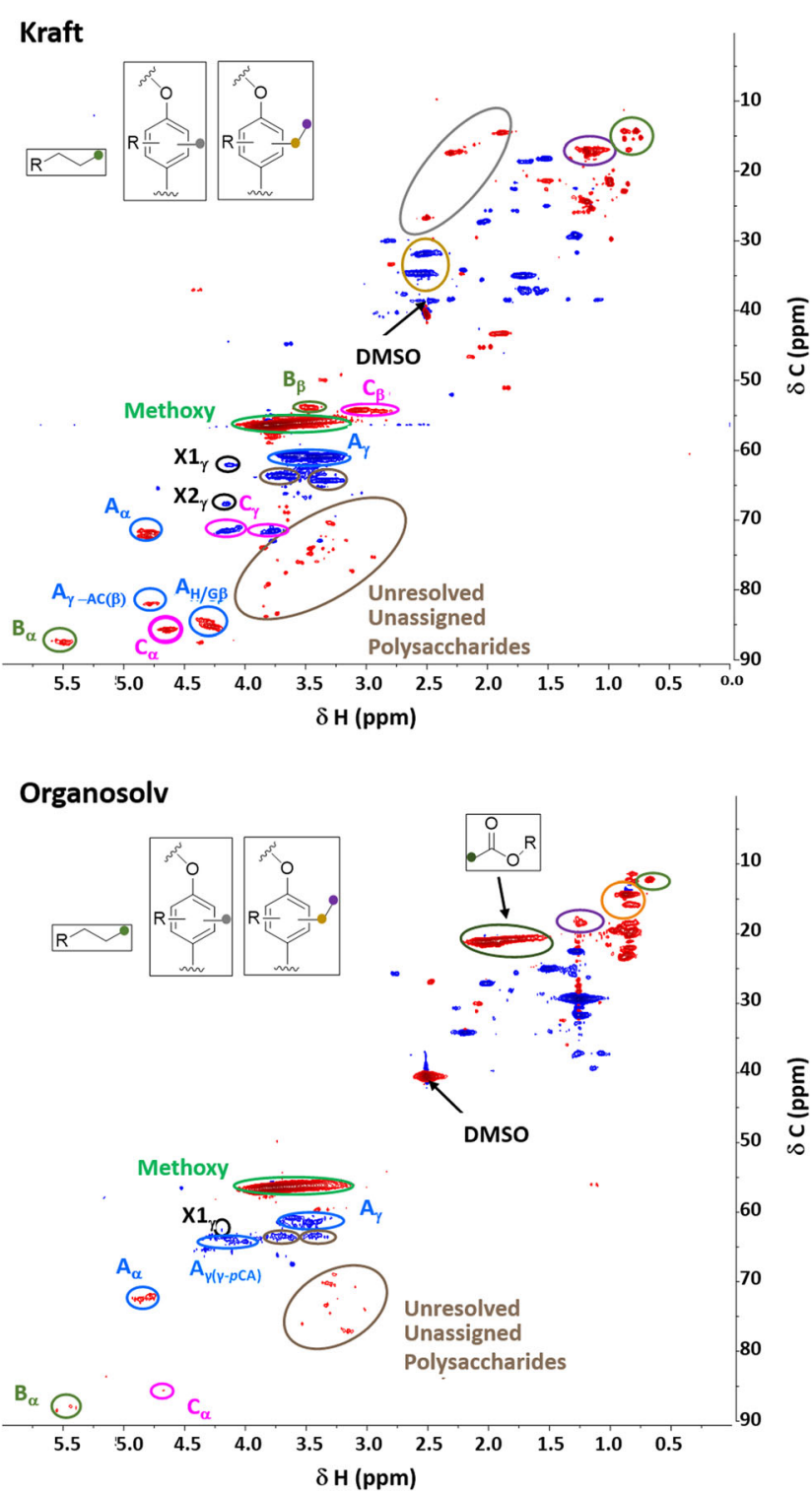

using different water/ethanol compositions varying between $100 / 0$ and $40 / 60$ were carried out under the conditions defined before (i.e., $225^{\circ} \mathrm{C}, 8 \mathrm{MPa}$, liquid flow and gas flow conditions being the same as reported in Section 3.2.1). In higher ethanol containing solvent mixture, lignin was not fully soluble, so for preventing the clogging of the tubular reactor, the higher ethanol limit content was fixed to $60 \mathrm{wt} \%$. Figure 2 clearly shows the impact of adding ethanol on the distribution of the three product fractions. In pure water, only $2 \%$ OP was obtained together with $35 \% \mathrm{AP}$ and $62 \% \mathrm{PM}$. Noticeably, the last is slightly higher to the Klason lignin value of initial lignin (i.e., 47\% KP). This indicates that condensation of small fragments occurred when pure water was used as the solvent. 
Table 5 Summary of technical lignin analysis

\begin{tabular}{|c|c|c|c|c|}
\hline Lignin & Alkaline lignin & Kraft lignin & Protobind 1000 & Organosolv lignin \\
\hline Initial biomass & Spruce & Maritime pine & $\begin{array}{l}\text { Wheat straw and } \\
\text { Sarkanda grass }\end{array}$ & Wheat straw \\
\hline Pulping process & Kraft & Kraft & Soda & Organosolv \\
\hline Klason lignin $(\%)$ & 47 & 87 & 83 & 85 \\
\hline Molecular weight (Da) & 3520 & 1740 & 2090 & 3880 \\
\hline$\% \mathrm{O}$ in $\mathrm{C}-\mathrm{O}-\mathrm{C}$ bonds & n.d. & $6 \%$ & $6 \%$ & $8 \%$ \\
\hline Chemical groups ${ }^{\mathrm{a}}$ & $\begin{array}{l}\mathrm{G} / \mathrm{H}(93 / 7) \\
\beta-\mathrm{O}-4(4.7)^{\mathrm{b}} \\
\mathrm{F} \text {, aliphatic, methoxy }\end{array}$ & $\begin{array}{l}\mathrm{G} / \mathrm{H}(88 / 12) \\
\beta-\mathrm{O}-4(14.2)^{\mathrm{b}} \\
\mathrm{F} \text {, aliphatic, methoxy }\end{array}$ & $\begin{array}{l}\mathrm{G} / \mathrm{S} / \mathrm{H}(53 / 34 / 13) \\
\beta-\mathrm{O}-4(3.5)^{\mathrm{b}} \\
\text { FA, aliphatic, carboxyl, } \\
\quad \text { methoxy, coumarate }\end{array}$ & $\begin{array}{l}\mathrm{G} / \mathrm{S} / \mathrm{H}(67 / 23 / 10) \\
\beta-\mathrm{O}-4(11.5)^{\mathrm{b}} \\
\text { FA, aliphatic, carboxyl, methoxy, } \\
\quad \text { coumarate, quinone }\end{array}$ \\
\hline Remarks & $\begin{array}{l}\text { - No syringyl } \\
\text { - High inorganic content }\end{array}$ & $\begin{array}{l}\text { - No syringyl } \\
\text { - OH guaiacyl abundant }\end{array}$ & - Carboxyl abundant & - Aliphatic abundant \\
\hline
\end{tabular}

$G$ guaiacyl, $H$ hydroxyphenyl, $S$ syringyl, $F$ ferulate

${ }^{\text {a }}$ From HSQC

${ }^{\mathrm{b}}$ Expressed per 100 aromatic units. Calculated from the HSQC spectra following the procedure reported in the Supporting information

Adding ethanol resulted in decreased amount of PM from 63 to $25-29 \%$ in favor of OP fraction that rises from 2 to $35 \%$. Except small variations, AP remains constant after growing from $35 \%$ in pure water to ca. $40-44 \%$ when ethanol was used. Two factors can be advanced for explaining these observations:

(i) Adding ethanol favors lignin fragmentation, either by increased solubility or consecutive reaction with the product so that they are more stable under the reaction conditions, leading therefore to increased amount of low molecular weight compounds in OP.

(ii) Ethanol reacts with some of the lignin fragments so that they are then soluble in OP either directly or via radical routes [15].

The first argument is evidenced by the increase of the GCdetected and quantified products, the latter by the ether signal on the HSQC spectra. Improved solubility does not necessarily mean better conversion; indeed, $\mathrm{Ni}$ and $\mathrm{Hu}$ showed that optimum lignin removal was observed in the Alcell process for ethanol concentration 55-70\% [40]. An optimum for lignin conversion was also observed when ethanol concentration was around 50-65 wt\% [41, 42]. The synergetic effect of water and ethanol on lignin is not fully explained. Nevertheless, this observation can only have a positive outcome on the process as water is cheaper than ethanol.

The fractionation of alkaline lignin before reaction yielded only $2-3 \%$ OP products. Hence, the solvolysis of lignin with a mixture $50 / 50$ water/ethanol led to multiply by a factor of 10 the yield in organic products.

GC analysis of the OP products (small molecules) shows that the effect of ethanol is rather limited until the 50/50 ratio is reached; in fact, the yield of identified monomers remained stable at about $2-4 \mathrm{mg} / \mathrm{g}_{\text {lignin }}$ (Table 6). Guaiacol remains the main product in all the experiments that can be assumed to be a relatively stable end product. With the exception of vanillin, most of the product yields were increased; it is likely that vanillin degradation occurred in the presence of ethanol. Para ethylated, methylated, and propylated products are observed when there was an important amount of ethanol. The identified products correspond to those already described in hydrothermal conversion of lignin at low temperature [21, 30]. They are lines of evidence that ethanol is evolved in the reaction scheme, either by stabilizing phenolics from undergoing condensation reactions or by reacting with lignin to form stable products. Alkylation at para position with fragments from ethanol was suggested by Hensen et al. during

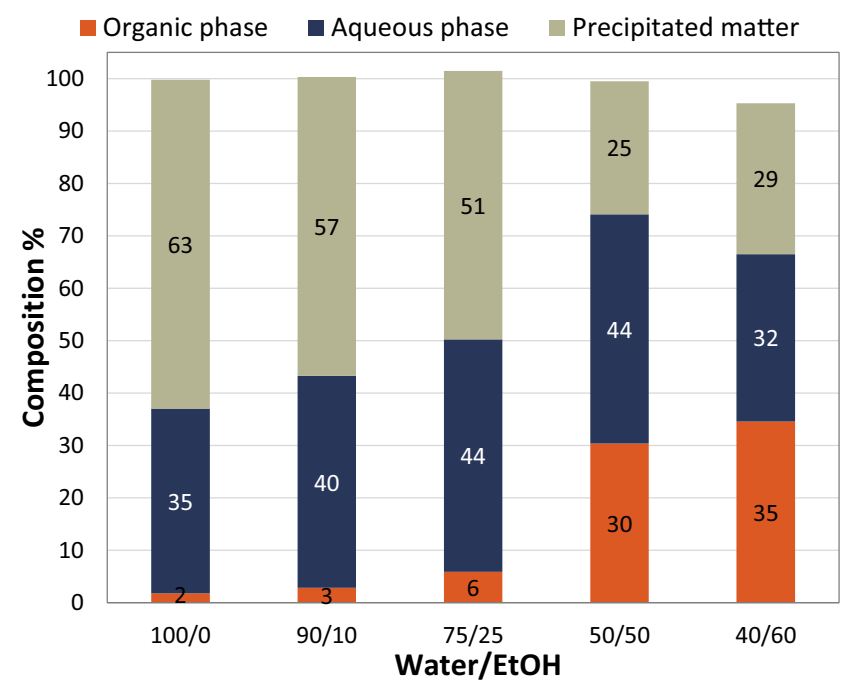

Fig. 2 Composition of reaction products after hydrolysis/solvolysis of alkaline lignin. Reaction conditions: $225^{\circ} \mathrm{C}, 1 \mathrm{wt} \%$ lignin in water/ethanol, $8 \mathrm{MPa}, 10 \mathrm{NL} \mathrm{h}^{-1} \mathrm{~N}_{2}$, no base 
Table 6 Composition of the organic phase $\mathrm{mg} / \mathrm{g}_{\text {lignin }}$ effect of ethanol concentration

\begin{tabular}{|c|c|c|c|c|c|}
\hline \multirow[t]{2}{*}{ Monomers yield $\left(\mathrm{mg} / \mathrm{g}_{\text {lignin }}\right)$} & \multicolumn{5}{|c|}{ Water/ethanol ratio } \\
\hline & $\begin{array}{l}100 / \\
0\end{array}$ & $\begin{array}{l}90 / \\
10\end{array}$ & $\begin{array}{l}75 / \\
25\end{array}$ & $\begin{array}{l}50 / \\
50\end{array}$ & $\begin{array}{l}40 / \\
60\end{array}$ \\
\hline Phenol & - & - & 0.1 & 0.4 & 2.6 \\
\hline Guaiacol & 1.2 & 1.2 & 2.2 & 4.0 & 18.6 \\
\hline Creosol & - & - & - & 0.2 & 0.9 \\
\hline 5-Methylguaiacol & - & - & - & 0.2 & 0.9 \\
\hline Vanillin & 2.1 & 2.1 & 1.2 & 0.3 & - \\
\hline$p$-Ethylguaiacol & - & - & 0.1 & 1.5 & 3.4 \\
\hline 2,6-Methoxyphenol & - & - & - & 0.1 & 0.4 \\
\hline Eugenol & - & - & - & 0.5 & 0.6 \\
\hline Isoeugenol & - & - & 0.1 & 0.4 & 0.5 \\
\hline Acetovanilone & 0.8 & 0.8 & 0.7 & 01.0 & 2.1 \\
\hline$p$-Propylguaiacol & - & - & 0.1 & 0.2 & 0.7 \\
\hline Homovanillyl alcohol & - & - & 0.2 & - & 0.8 \\
\hline Guaiacylacetone & 1.2 & 1.1 & 0.4 & 1.1 & 1.1 \\
\hline Ethylhomovanillate & - & - & 0.6 & 1.0 & 1.1 \\
\hline Ethyl-3-(4-hydroxy-3-methoxyphenyl)propionate & - & - & - & 0.3 & 0.8 \\
\hline Total & 5.4 & 5.0 & 5.8 & 11.4 & 34.6 \\
\hline
\end{tabular}

supercritical ethanol treatment of lignin [15]. In the case of our study, it is difficult to draw such conclusions due to very different reaction conditions, but ethanol definitely helps produce alkylated products. Next to helping lignin fragmentation, ethanol probably participates in the reaction producing alkylated compounds either by direct alkylation or more probably via radical mechanisms, as ethanol is being known to act as a radical scavenger. On the GC spectrum, products issued from side reactions of ethanol were observed; mainly, it was highlighted that ethanol delivers higher alcohols as well as esters and acids. The formation of such side products is probably catalyzed by the slightly basic reaction media ( $\mathrm{pH} 8-9$ ) that initiates dimerization and esterification [43]. Furanic derivatives were not included in the table as they are most likely derived from the carbohydrates present in lignin samples.

Detailed characterizations of OP and PM fractions The fractions from solvolysis of alkaline lignin conducted at $225^{\circ} \mathrm{C}$, $50 / 50$ water/ethanol mixture, were analyzed in detail by a multitechnique approach.

${ }^{31} \mathrm{P}$ NMR of the organic phase showed the prevalence of hydroxyl groups belonging to guaiacyl and condensed phenolics. When we compare the OP fraction to the initial lignin, the amount of aliphatic hydroxyl groups was reduced (Table 7). The removal of polysaccharide moieties can decrease the hydroxyl present in the sample, but alkylation of hydroxyl groups and liberation of small alcohols are more likely to explain this decrease. As a reminder, the amount of polysaccharides present in lignin represents only a small fraction (less than $2 \%$ ). The $\mathrm{G}$ units in the OP fraction are also increased.
The amount of condensed phenolics in the OP fraction decreased.

The analysis of the OP fraction by HSQC (Fig. 3) showed that most of the $\beta-\mathrm{O}-4$ linkages $\left(A_{x \beta}, x=G, H\right.$, or $\left.S\right)$ are cleaved, and it is evident that under our condition, $\mathrm{C}-\mathrm{O}-\mathrm{C}$ are more reactive than condensed structures [44]. Some condensed linkages are preserved specially resinol structures $(\mathrm{Cx})$, consistent with ${ }^{31} \mathrm{P}$ NMR observations. The polysaccharides present in the initial lignin samples were also removed; hydrolysis under this condition is very likely. Major changes are observed in the aliphatic region (side chain), and the intensity of $p$-methylated, $p$-ethylated, and $p$-propylated phenol structures is increased. It is hard to distinguish propylated phenolics from other alkyls issued from alcohol reacting with itself (i.e., Guerbet reaction) under the basic conditions used without excluding the participation of metal traces present in starting alkaline lignin (see Table S1) [45-47], as the peaks will be on the same zone. Since $p$-propylated products are observed with GC, it is fair to assume that $p$-propylated phenolics are present in that area. The well-documented role of ethanol as a radical scavenger [18] is also preserved here. The radical scavenging properties of ethanol are well known, and this alcohol is even added to some solvents as a stabilizing agent. Thus, having more ethanol in the reaction media will prevent condensation reactions; indeed, during depolymerization, highly reactive radials are formed, and in the absence of other nucleophilic species in the media, they will recombine [48]. While the reaction conditions are rather different, these observations are supported by those made by Hensen et al. 
Table $7 \quad{ }^{31} \mathrm{P}$ NMR results for alkaline lignin before and after solvolysis

\begin{tabular}{lllll}
\hline & & $\begin{array}{l}\text { Alkaline lignin before } \\
\text { solvolysis }\end{array}$ & $\begin{array}{l}\text { After solvolysis } \\
(\mathrm{OP})\end{array}$ & $\begin{array}{l}\text { After solvolysis } \\
(\mathrm{PM})\end{array}$ \\
\hline Total hydroxyl groups $\left(\mathrm{mmol}_{\mathrm{OH}} \mathrm{g}^{-1}\right)$ & & 5.9 & 2.7 & 4.6 \\
Distribution of $-\mathrm{OH}$ groups $(\%)$ & $-\mathrm{OH}$ in aliphatic moieties & 25 & 18 & 38 \\
& $-\mathrm{OH}$ in condensed phenolic moieties & 45 & 30 & 54 \\
& $-\mathrm{OH}$ in guaiacyl moieties & 18 & 2 & 22 \\
& $-\mathrm{OH}$ in hydroxyphenyl moieties & 3 & 12 & 2 \\
& $-\mathrm{OH}$ in carboxyl moieties & 9 & 9
\end{tabular}

Reaction conditions: $225^{\circ} \mathrm{C}, 1 \mathrm{wt} \%$ lignin in water/ethanol 50/50, $8 \mathrm{MPa}, 10 \mathrm{NL} \mathrm{h}^{-1} \mathrm{~N}_{2}$, no base

recently who showed the radical scavenging property of ethanol during the treatment of a soda lignin [18].

At this stage, it is difficult to assert if ethanol or ethanol fragments reacted directly at the para position, products like ethyl homovanillate, or ethyl 3-(4-hydroxy-3-methoxyphenyl)propionate can be cleaved on the side chain to give alkylated phenolics. Guaiacyl units are still in majority in the repartition of aromatic units $(99 \%)$.

In summary, the organic fraction is composed of ex-lignin oligomers containing chemical moieties characteristic of the starting material, i.e., aromatic guaiacyl, hydroxyphenyl, and ferulate groups, as well as aliphatic groups. The level of ether bonds drastically decreased during solvolysis. Monomers of interest for chemical industry were also detected, such as guaiacol and vanillin, and represent $7 \%$ of the organic fraction. Increasing the percentage of ethanol in the solvent mixture led to increase the lignin depolymerization and changed the composition of the obtained products.

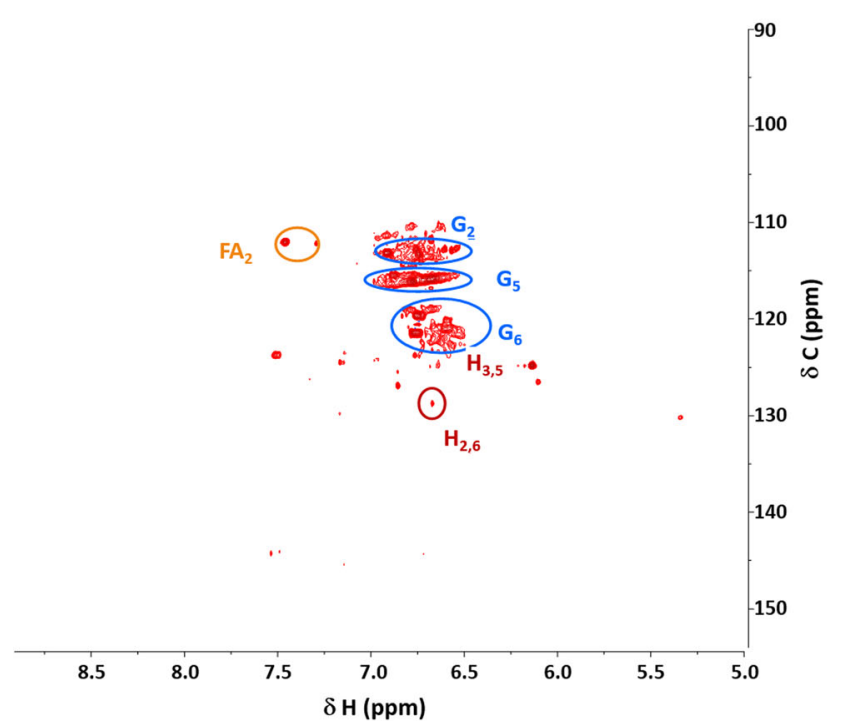

The PM fraction is compared to the initial lignin feedstock to see if the residual matter remained the same or was altered. The comparison between initial lignin and the PM fraction of the ${ }^{31} \mathrm{P}$ NMR shows that the total amount of hydroxyl groups was reduced. This can be attributed to the liberation of $\mathrm{G}, \mathrm{H}$, and acid fragments to the solution, reducing thus the hydroxyl content in PM [49]. On the other hand, the condensed hydroxyl groups increased. This might be caused either by repolymerization reactions or due to the fact that other less recalcitrant structures are liberated to the solution; hence, condensed structures are concentrated on the residual solid. The HSQC spectrum of the PM showed significant decrease from 4.7 to 0.9 of the number of $\beta-\mathrm{O}-4$ linkages per 100 aromatic units, as expected (see Table S2).

The changes observed on infrared spectra are minor (see the ESI). Most of the functionalities are preserved, but changes in relative intensity are observed. On the alkaline lignin, the broad peak $1601-1710 \mathrm{~cm}^{-1}$ (attributed to aromatic skeletal vibrations and $\mathrm{C}=\mathrm{O}$ stretching) and the peak $1030-1040 \mathrm{~cm}^{-1}$

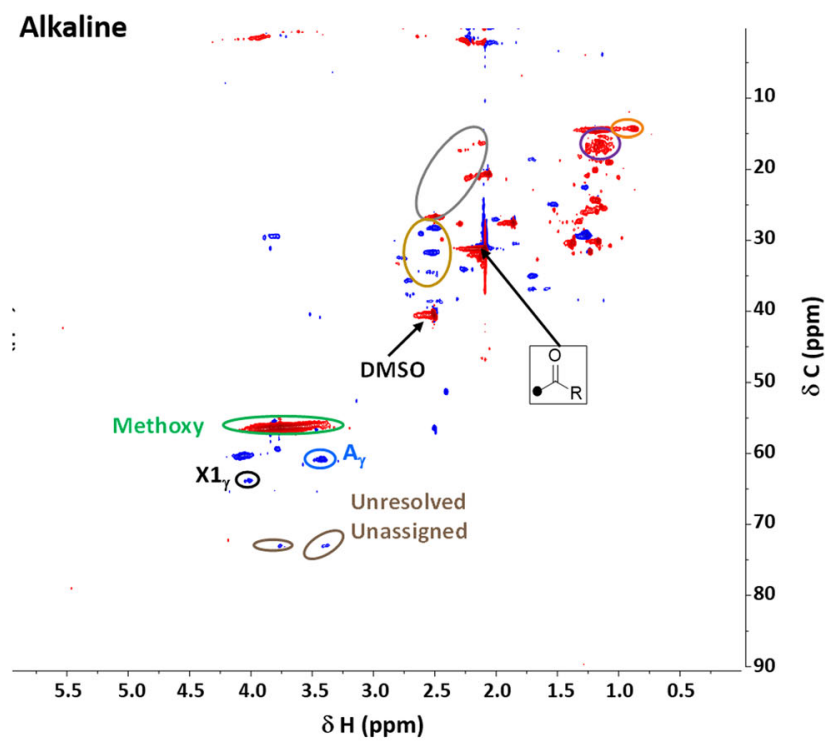

Fig. 3 HSQC spectra of OP fraction after solvolysis of alkaline lignin. Left: side chain region. Right: aromatic region. Reaction conditions: $225^{\circ} \mathrm{C}$, $1 \mathrm{wt} \%$ lignin in water/ethanol 50/50,8 MPa, $10 \mathrm{NL} \mathrm{h}^{-1} \mathrm{~N}_{2}$, no base 
(attributed to aromatic $\mathrm{C}-\mathrm{H}$ in-plane deformation, $\mathrm{C}-\mathrm{O}$ deformation in primary alcohols, and $\mathrm{C}=\mathrm{O}$ stretching) were highly reduced. The characteristic peak for $\mathrm{G}$ units at $1140 \mathrm{~cm}^{-1}$ was reduced in accordance with ${ }^{31} \mathrm{P}$ NMR observation.

The molecular weight of solid fraction was determined by SEC analysis and was equal to $2180 \mathrm{Da}$, i.e., a decrease of $38 \%$ compared to the starting material.

Finally, the analysis of PM fraction shows that the composition of solid is similar to the starting material, unless the amount of free hydroxyls slightly decreased and the molecular weight drastically decreased, which indicates an efficient depolymerization of lignin during solvolysis. The presence of char or char precursor in the solid fraction is unlikely.

For the next experiments, a 50/50 water/EtOH ratio was studied since the PM fraction is at the lowest and due to the relatively satisfactory mass balance obtained.

\subsection{Solvolysis of other technical lignins}

Kraft lignin, Protobind, and organosolv lignins were not completely soluble at neutral $\mathrm{pH}$ in a 50/50 water/ethanol mixture; $0.1 \mathrm{wt} \% \mathrm{~K}_{2} \mathrm{CO}_{3}$ was added to the feed to increase lignin solubility. Reactions were conducted under the conditions reported in Section 3.2.2.1 (i.e., $225^{\circ} \mathrm{C}, 8 \mathrm{MPa}$, liquid flow $20 \mathrm{~mL} / \mathrm{h}$, gas flow $10 \mathrm{~L} / \mathrm{min}$ ). As for alkaline lignin, reaction mixtures were fractionated into $\mathrm{OP}, \mathrm{AP}$, and $\mathrm{PM}$ product fractions to allow careful analysis of the products obtained.

When $0.1 \mathrm{wt} \%$ of $\mathrm{K}_{2} \mathrm{CO}_{3}$ was added, kraft lignin was also entirely soluble, and there were some insoluble particles for the Protobind and organosolv lignins which were removed by centrifugation from the solution and disregarded from the mass balance. For the sake of comparison, base was added to the entirely soluble alkaline lignin sample. It is noticeable that the addition of base did not change the total OP product yield but slightly increased the monomers yield (from 11 to $22 \mathrm{mg} / \mathrm{g}_{\text {lignin }}$, total of identified monomers). The mass balance is very variable under the conditions investigated. Organosolv lignin gave poor mass balance, probably due to the formation of either insoluble components trapped inside the reactor, which are hard to quantify or products evolving in gas phase. The comparison of the phase distribution between different lignins is irrelevant as the samples do not have the same physicochemical properties. To gain insight on the relative recalcitrance of one sample, comparing the amount of AP and PM fraction to the acid-soluble and Klason lignin (acid insoluble) of the initial lignin can be useful. Initial Klason lignin contents for alkaline lignin, kraft, Protobind 1000, and organosolv lignins are $47,87,82$, and $85 \%$ (Table 2) and were reduced by $24,54,36$, and $40 \%$, respectively (Fig. 4). Based on this reduction, it can be concluded that Protobind and organosolv lignin were more efficiently liquefied.

The analysis of the organic phases followed the same trend (Table8). The Protobind lignin gave higher yields of

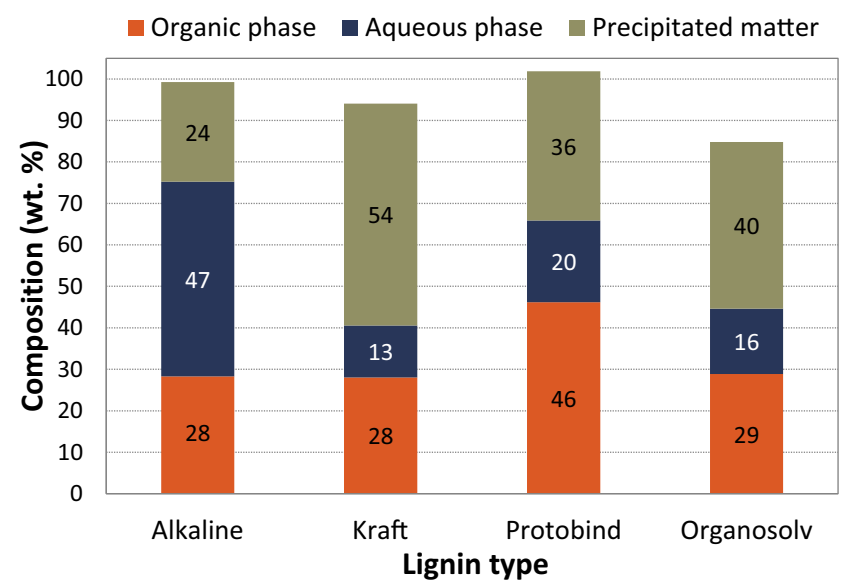

Fig. 4 Composition of reaction products after solvolysis of technical lignin. Reaction conditions: $225^{\circ} \mathrm{C}, 1 \mathrm{wt} \%$ lignin in water/ethanol, $8 \mathrm{MPa}, 10 \mathrm{NL} \mathrm{h}^{-1} \mathrm{~N}_{2}, 0.1 \mathrm{wt} \% \mathrm{~K}_{2} \mathrm{CO}_{3}$

monomers compared to the other lignins. The organosolv and Protobind lignin were prepared from annual plants; therefore, they contain $\mathrm{G}, \mathrm{S}$, and $\mathrm{H}$ type of units which explains the new components (syringyl and $p$-hydroxyphenyl derivatives). Lignins containing $\mathrm{S}$ units are less liable to condensation than samples without sinapyl units, as the positions 3 and 5 are occupied by methoxy groups. This can reduce the chance of $\mathrm{C}-\mathrm{C}$ interunit linkage formation [50]. Both alkaline and kraft lignins gave similar results despite the different contents of Klason lignin. Despite the higher number of $\beta-\mathrm{O}-4$ linkages in kraft and organosolv lignins, the yields in monomeric aromatic compounds in OP was not significantly improved probably due to either recondensations or products evolving in gas phase. Nevertheless, it is reasonable to support that the process applied here for lignin solvolysis really cleaved such $\beta-O-4$ linkages as their number significantly decreased in PM (see below).

Surprisingly, the alkaline lignin composed of $40 \%$ of acidsoluble products did not give improved yields of monomers. Actually, it is believed that acid-soluble compounds are mainly smaller oligomers, which are easier to cleave than bigger fragments, to form monomeric compounds (Table 8).

All organic fractions were analyzed by ${ }^{31} \mathrm{P}$ NMR after phosphitylation. Comparing the OP fraction to the initial lignin for the kraft lignin showed that the amount of aliphatic hydroxyl groups was highly reduced. This trend is also observed with the other lignin samples but with a lower magnitude. The removal of polysaccharide moieties can decrease the hydroxyl present in the sample, but alkylation of hydroxyl groups and liberation of small alcohols are more likely to explain this decrease. As a reminder, the amount of polysaccharides present in the lignin represents only a small fraction (less than 2\%). The G units in the OP fraction are also increased, but with different extent depending on the sample. For example, for the organosolv and the kraft lignins, we see an important increment of $\mathrm{G}$ hydroxyl groups in OP fraction. 
Table 8 Composition of the organic phase $\mathrm{mg} / \mathrm{g}_{\text {lignin }}$ for different lignin samples

\begin{tabular}{lllll}
\hline Monomers & Alkaline lignin & Kraft & Protobind 1000 & Organosolv \\
\hline Phenol & 0.7 & 0.2 & 2.0 & 0.6 \\
Guaiacol & 9.8 & 9.7 & 5.2 & 3.3 \\
Creosol & 0.8 & 0.2 & 0.1 & 0.1 \\
$p$-Ethylphenol & - & - & 0.4 & 0.6 \\
5-Methylguaiacol & 0.4 & - & - & - \\
$p$-Vinylguaiacol & - & - & 0.4 & 1.0 \\
Vanillin & - & 0.9 & 1.7 & 1.3 \\
$p$-Ethylguaiacol & 2.9 & 0.8 & 0.9 & 1.6 \\
2,6-Methoxyphenol & 0.2 & 0.2 & 9.5 & 3.9 \\
Eugenol & 0.4 & 0.3 & - & - \\
Isoeugenol & 0.4 & 0.2 & 0.4 & 1.6 \\
Acetovanilone & 2.8 & 2.1 & 1.0 & 1.4 \\
$p$-Propylguaiacol & 0.5 & 0.4 & - & - \\
Homovanillyl alcohol & 0.9 & 0.4 & - & - \\
Ethyl (3-hydroxyphenyl) acetate & - & - & 0.3 & 0.3 \\
Guaiacylacetone & 1.0 & 2.7 & 0.9 & 1.4 \\
Syringaldehyde & - & - & 2.8 & 1.0 \\
2-Ethoxy-6-(methoxymethyl) phenol & - & - & 0.5 & 0.3 \\
Methoxyeugenol & - & - & 0.4 & 0.5 \\
Acetosyringone & - & - & $8, .5$ & 4.0 \\
Ethyl homovanillate & 0.8 & 0.3 & - & 0.9 \\
Ethyl 3-(4-hydroxy-3-methoxyphenyl)propionate & 0.3 & 20.0 & 36.1 & - \\
Total identified & 22.1 & & & \\
\hline & & -1.5 & \\
\hline
\end{tabular}

The amount of condensed phenolics in OP fraction decreased for the kraft lignins (alkaline and kraft). The Protobind and organosolv lignins contain $\mathrm{S}$ units; these units cannot be quantified separately from condensed phenolics since their signals overlap (Fig. 5). Hence, the increase observed with the red data set can either be linked to increase in $\mathrm{S}$ units or condensed phenolics.

The HSQC spectra are presented in Fig. 6. The analysis of the OP fraction by HSQC showed that most of the $\beta-\mathrm{O}-4$ linkages $\left(A_{x \beta}, x=G, H\right.$, or $\left.S\right)$ are cleaved; it is evident that under our condition, $\mathrm{C}-\mathrm{O}-\mathrm{C}$ are more reactive than condensed structures [44]. Some condensed linkages are preserved specially resinol structures $(\mathrm{Cx})$, consistent with ${ }^{31} \mathrm{P}$ NMR observations. For the alkaline kraft and organosolv lignins that have low ratio of ether linkages, no information is provided by this analysis. As exposed before, polysaccharides were fully converted during the reaction.

Major changes are observed in the aliphatic region (side chain), and the intensity of $p$-methylated, $p$-ethylated, and $p$ propylated phenol structures is increased. Despite difficulty in distinguishing propylated phenolics from other alkyls issued from Guerbet condensation, it is fair to assume that $p$ propylated phenolics are present in that area, since $p$-propylated products are observed in GC. In the absence of other data, it is difficult to assert if ethanol or ethanol fragments reacted directly at the para position, some products being potentially obtained by direct cleavage from lignin (i.e., ethyl homovanillate, ethyl 3-(4-hydroxy-3-methoxyphenyl)propionate). Like before, the role of ethanol as a radical scavenger is preserved.

Acetyl fragment characterized by the peak centered at 20.8/ $2.28(\delta \mathrm{C} / \delta \mathrm{H})$ present in the initial organosolv lignin evidently disappeared in the OP fraction. In all the samples, the correlation signal for methoxy groups (56.3/3.7) remained intense, as demethylation did not occur with our approach. Signals

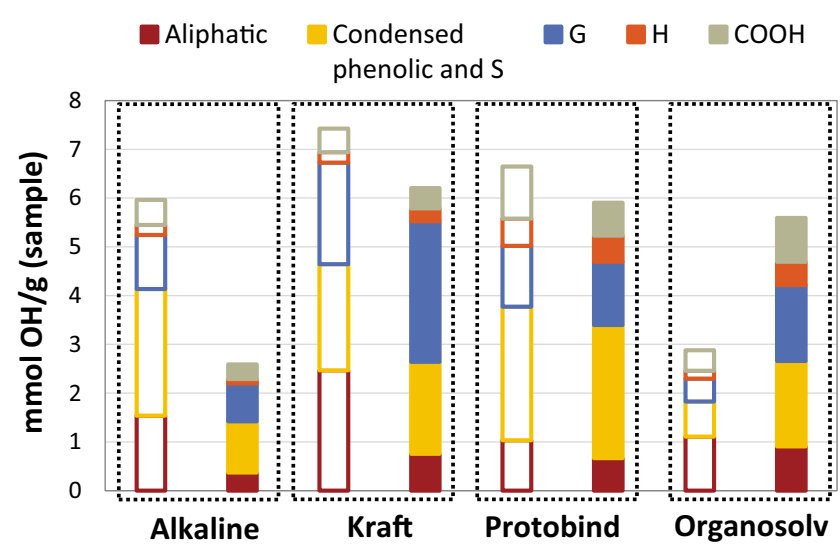

Fig. 5 Concentration of $\mathrm{OH}$ groups in technical lignins (empty bars) and in OP fractions (plain bars) 

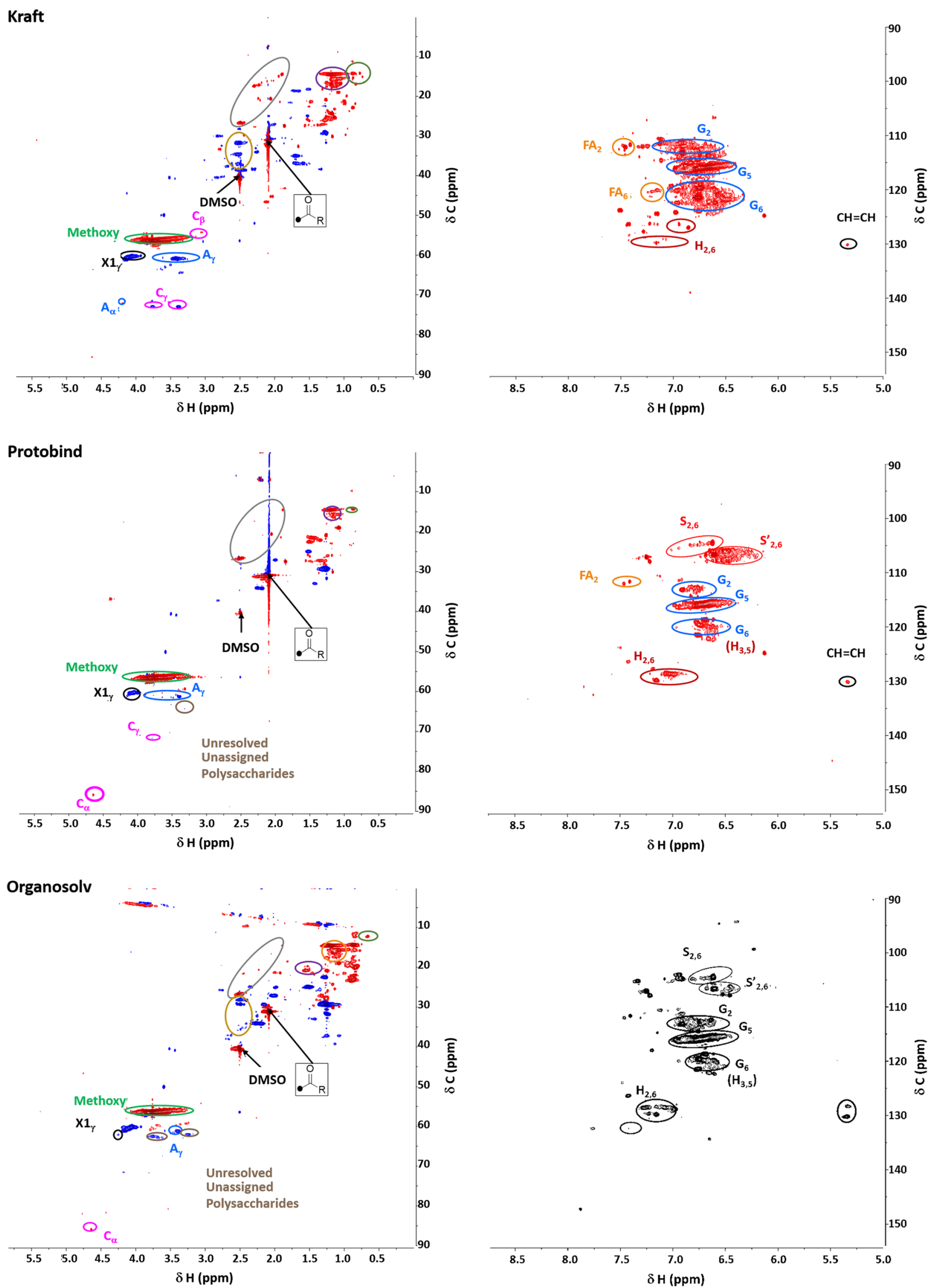

Fig. 6 HSQC spectra of OP fractions after solvolysis of technical lignins. Left: side chain region. Right: aromatic region 
from dibenzodioxocin (5-5 and $\beta-\mathrm{O}-4)$ and spirodienone ( $\beta$ 1) were not visible on either, probably because their concentration is very low or because they are nonexistent.

With the limitations exposed previously, the HSQC spectra delivered information on the evolution $\mathrm{G} / \mathrm{H} / \mathrm{S}$ aromatic units between the initial feedstock and the $\mathrm{OP}$ fraction. In the aromatic region, the difference in composition in terms of $p$ hydroxyphenyl, guaiacyl, and syringyl (H/G/S) can be clearly distinguished. For the OP fraction, the aromatic region is well resolved as this fraction contains most of the phenolic fragments. For kraft and alkaline lignins, the comparison between initial lignin samples and the OP fraction shows that the $\mathrm{H}$ units are reduced. Indeed, $\mathrm{H}$ units are more prone to condensation reaction because the 5 and 3 positions on the aromatic ring are not blocked by the methoxy group. For the organosolv lignin, the relative $\mathrm{H}$ content remained unchanged, while a minor change was observed for the $\mathrm{G} / \mathrm{S}$ ratio. Please note that reduction of the unsaturation at 7 and 8 positions of the side chain will give rise to $\mathrm{H}$ units which might explain the absence of its relative content for the Protobind and organosolv lignins. $p$-Coumarate signals were only present in Protobind and organosolv lignins whose intensity was highly reduced in the OP fraction.

To summarize, the yield and composition of the organic phase are impacted by the type of lignin used as a starting material. The Protobind lignin gave the highest yield organic fraction (46\%), and all the other lignins yielded around 30\% organic products. In all cases, the part of monomers is minor in the organic fraction, around $7 \%$ of the total of oligomers. However, the chemical composition of monomers depends on the starting material; kraft lignins tend to yield guaiacol and acetovanilone as major monomers, whereas Protobind and organosolv lignins give more diversified monomers, including syringaldehyde and acetosyringone. Obviously, the nature of monomers is impacted by the type of biomass (Protobind and organosolv lignins come from wheat straw) rather than the type of treatment. The removal of ether bonds during solvolysis was evidenced by HSQC analysis in all cases.

In general, the comparison of ${ }^{31} \mathrm{P}$ NMR spectra between phosphitylated samples of initial lignin and PM fractions shows that the total hydroxyl groups were reduced in all samples with the exception of the organosolv lignin (Fig. 7). Indeed, for the PM fraction, the phenolics and aliphatics for all the lignins, except for organosolv, were reduced. This can be attributed to the liberation of $\mathrm{G}, \mathrm{H}, \mathrm{S}$, and acid fragments in the solution, reducing thus hydroxyl content in PM [49]. On the other hand, the condensed hydroxyl groups increased in all the samples. This might be caused either by repolymerization reactions or due to the fact that other less recalcitrant structures are liberated to the solution; hence, condensed structures are concentrated in the residual solid. The unique behavior observed for the organosolv lignin comes from the fractionation step; actually, the organosolv lignin is obtained from treatment using a mixture of acetic acid and formic acid; therefore, some

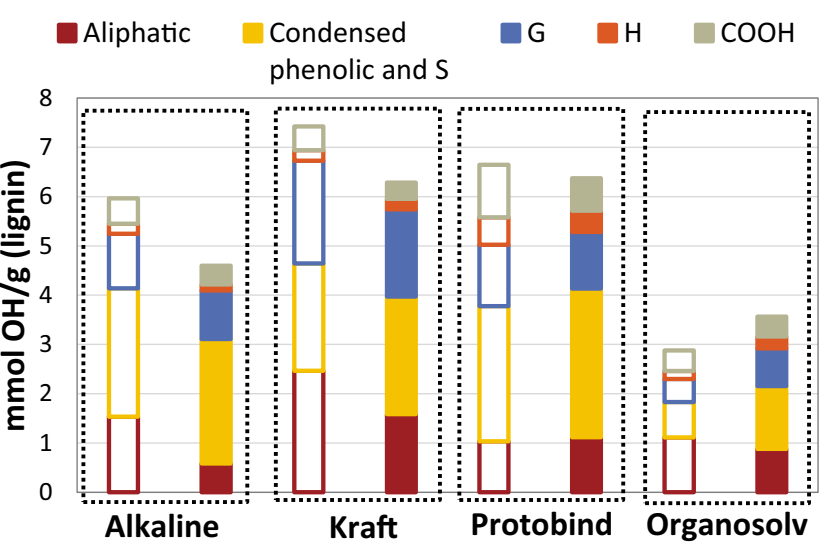

Fig. 7 Concentration of $\mathrm{OH}$ groups in technical lignins (empty bars) and in PM fractions (plain bars)

hydroxyl groups are esterified [51]. During our treatment, saponification reactions might have occurred thus increasing the hydroxyl groups in the PM fraction. Like for alkaline, the HSQC spectra of the PM fraction showed a significant decrease of the number of $\beta-\mathrm{O}-4$ linkages per 100 aromatic units in the residual solid from 14.2 to 3.7 for the kraft lignin, 3.5 to 0.6 for the P1000, and 11.5 to 0.5 for the organosolv lignin. These data are coherent with other analyses of this fraction and that of the organic fraction (i.e., OP) and indicate clearly cleavages of such bonds during solvolysis reactions (see Table S2).

Like before, the changes observed on the FT-IR spectra of lignin and PM are minor (see Electronic supporting information). On the alkaline lignin, the broad peak at 1601$1710 \mathrm{~cm}^{-1}$ (attributed to aromatic skeletal vibrations and $\mathrm{C}=\mathrm{O}$ stretching) and the peak at $1030-1040 \mathrm{~cm}^{-1}$ (attributed to aromatic $\mathrm{C}-\mathrm{H}$ in-plane deformation, $\mathrm{C}-\mathrm{O}$ deformation in primary alcohols, and $\mathrm{C}=\mathrm{O}$ stretching) were highly reduced. The characteristic peaks for $\mathrm{G}$ units at $1140 \mathrm{~cm}^{-1}$ were reduced in accordance with ${ }^{31} \mathrm{P}$ NMR observation. For the kraft lignin, almost no difference between the initial and the treated lignin was observed. For the Protobind 1000 lignin, a slight decrease of the peak at $1326 \mathrm{~cm}^{-1}$ is attributed to $S$ units and condensed $\mathrm{G}$ units. For the organosolv lignin, the peaks for $\mathrm{C}=\mathrm{O}$ stretch and aromatic skeletal vibrations (1701$1650 \mathrm{~cm}^{-1}$ ) were reduced.

The SEC analysis of the PM fraction shows that the residual solid molecular weight is in general reduced compared to initial lignin (the chromatograms are available in the ESI). The molecular weight of the alkaline and the organosolv lignins was highly reduced by almost half. The polydispersity index (PDI) also narrowed a decrease of 16 and $27 \%$, respectively. The kraft and the Protobind lignins are less altered but the low Mw shoulders were systematically increased. Also, the initial molecular weight was lower for these samples. In general, the higher the Mw, the higher the decrease, a trend also observed previously [52]. 
In summary, the precipitated matter samples show chemical properties close to the initial technical lignins. Therefore, PM can be considered as unreacted lignin and the formation of char is unlikely in our reaction conditions. The major noticeable change is the reduction of molecular mass, attributed to the depolymerization of lignin. However, it seems that depolymerization/recondensation reactions lead to a resilient lignin residue around $20 \mathrm{kDa}$; technical lignins such as $\mathrm{kraft}$ and Protobind with low initial molecular mass do not lead to a significant decrease in molecular mass.

\section{Conclusion}

The feasibility of a continuous process for the solvolysis of technical lignins was demonstrated. After optimizing the reaction conditions using alkaline lignin, we found that working at $225^{\circ} \mathrm{C}$ under $8 \mathrm{MPa}$ nitrogen in a $1-\mathrm{wt} \%$ basic water/ ethanol 1/1 mixture allowed to operate the reactor without observing char, nor foam, formation. Under these reaction conditions, several lignins coming from various lignocelluloses (softwood, wheat straw) and various treatments (kraft, soda, organosolv) were converted into monomers (guaiacol, vanillin, etc.) and oligomers. The product yields and distribution depend mainly on the type of biomass: wheat straw gave more diversified monomer products, including syringaldehyde, than softwood. The treatment applied to produce lignin does not seem to influence the final yields of solvolysis to a large extent.

Depolymerization of lignin was observed as well as recondensation reactions. A resilient lignin residue seems to appear around a molecular mass of $20 \mathrm{kDa}$. In the near future, catalysts, either heterogeneous or homogeneous, will be used to improve depolymerization efficiency.

Author contributions The manuscript was written through contributions of all authors. All authors have given approval to the final version of the manuscript.

Funding information The authors gratefully acknowledge the National Agency of Research (CHEMLIVAL No. ANR-12-CDII-0001_01) for funding. W.S. thanks the French Ministry of Research and Education for the $\mathrm{PhD}$ grant.

\section{References}

1. Ragauskas AJ (2006) The path forward for biofuels and biomaterials. Science 311(80):484-489. https://doi.org/10.1126/science. 1114736

2. Vassilev SV, Baxter D, Andersen LK, Vassileva CG, Morgan TJ (2012) An overview of the organic and inorganic phase composition of biomass. Fuel 94:1-33. https://doi.org/10.1016/j.fuel.2011. 09.030

3. Terashima N (1989) An improved radiotracer method for studying formation and structure of lignin. pp 148-159
4. Parthasarathi R, Romero RA, Redondo A, Gnanakaran S (2011) Theoretical study of the remarkably diverse linkages in lignin. J Phys Chem Lett 2:2660-2666. https://doi.org/10.1021/jz201201q

5. Vishtal A, Kraslawski A (2011) Challenges in industrial applications of technical lignins. BioResources 6:3547-3568. https://doi. org/10.15376/BIORES.6.3.3547-3568

6. Constant S, Wienk HLJ, Frissen AE, Peinder P, Boelens R, van Es DS, Grisel RJH, Weckhuysen BM, Huijgen WJJ, Gosselink RJA, Bruijnincx PCA (2016) New insights into the structure and composition of technical lignins: a comparative characterisation study. Green Chem 18:2651-2665. https://doi.org/10.1039/ C5GC03043A

7. Gosselink RJA, de Jong E, Guran B, Abächerli A (2004) Coordination network for lignin — standardisation, production and applications adapted to market requirements (EUROLIGNIN). Ind Crop Prod 20:121-129. https://doi.org/10.1016/j.indcrop.2004.04.015

8. Botello JI, Gilarranz MA, Rodríguez F, Oliet M (1999) Preliminary study on products distribution in alcohol pulping of Eucalyptus globulus. J Chem Technol Biotechnol 74:141-148. https://doi.org/10. 1002/(SICI)1097-4660(199902)74:2<141::AID-JCTB1>3.0.CO;2-0

9. Wildschut J, Smit AT, Reith JH, Huijgen WJJ (2013) Ethanol-based organosolv fractionation of wheat straw for the production of lignin and enzymatically digestible cellulose. Bioresour Technol 135:5866. https://doi.org/10.1016/j.biortech.2012.10.050

10. Quesada-Medina J, López-Cremades FJ, Olivares-Carrillo P (2010) Organosolv extraction of lignin from hydrolyzed almond shells and application of the $\delta$-value theory. Bioresour Technol 101:82528260. https://doi.org/10.1016/j.biortech.2010.06.011

11. Pan X (2012) Organosolv biorefining platform for producing chemicals, fuels, and materials from lignocellulose. In: The role of green chemistry in biomass processing and conversion. Wiley, Hoboken, pp 241-262

12. Nitsos C, Stoklosa R, Karnaouri A, Vörös D, Lange H, Hodge D, Crestini C, Rova U, Christakopoulos P (2016) Isolation and characterization of organosolv and alkaline lignins from hardwood and softwood biomass. ACS Sustain Chem Eng 4:5181-5193. https:// doi.org/10.1021/acssuschemeng.6b01205

13. Oliet M, Garcia J, Rodriguez F, Gilarrranz MA (2002) Solvent effects in autocatalyzed alcohol-water pulping: comparative study between ethanol and methanol as delignifying agents. Chem Eng J 87:157-162. https://doi.org/10.1016/S1385-8947(01)00213-3

14. McDonough TJ (1992) The chemistry of organosolv delignification

15. Huang X, Korányi TI, Boot MD, Hensen EJM (2014) Catalytic depolymerization of lignin in supercritical ethanol. ChemSusChem 7:2276-2288. https://doi.org/10.1002/cssc.201402094

16. Miller JE, Evans L, Littlewolf A, Trudell DE (1999) Batch microreactor studies of lignin and lignin model compound depolymerization by bases in alcohol solvents. Fuel 78:1363-1366. https://doi.org/10.1016/S0016-2361(99)00072-1

17. Voitl T, Von Rohr PR (2010) Demonstration of a process for the conversion of kraft lignin into vanillin and methyl vanillate by acidic oxidation in aqueous methanol. Ind Eng Chem Res 49: 520-525. https://doi.org/10.1021/ie901293p

18. Huang X, Korányi TI, Boot M, Hensen EJM (2015) Ethanol as capping agent and formaldehyde scavenger for efficient depolymerization of lignin to aromatics. Green Chem 17:4941-4950. https:// doi.org/10.1039/C5GC01120E

19. Song Q, Wang F, Cai J, Wang Y, Zhang J, Yu W, Xu J (2013) Lignin depolymerization (LDP) in alcohol over nickel-based catalysts via a fragmentation-hydrogenolysis process. Energy Environ Sci 6:994. https://doi.org/10.1039/c2ee23741e

20. Abdelaziz OY, Li K, Tunå P, Hulteberg CP (2018) Continuous catalytic depolymerisation and conversion of industrial kraft lignin into low-molecular-weight aromatics. Biomass Convers Biorefinery 8: 455-470. https://doi.org/10.1007/s13399-017-0294-2 
21. Beauchet R, Monteil-Rivera F, Lavoie JM (2012) Conversion of lignin to aromatic-based chemicals (L-chems) and biofuels (Lfuels). Bioresour Technol 121:328-334. https://doi.org/10.1016/j. biortech.2012.06.061

22. Schmiedl D, Endisch S, Pindel E et al (2012) Base catalyzed degradation of lignin for the generation of oxy-aromatic compoundspossibilities and challenges. Erdöl Erdgas Kohl 10:357-363

23. Rinaldi R, Jastrzebski R, Clough MT, Ralph J, Kennema M, Bruijnincx PCA, Weckhuysen BM (2016) Paving the way for lignin valorisation: recent advances in bioengineering, biorefining and catalysis. Angew Chemie Int Ed 55:8164-8215. https://doi.org/10. 1002/anie.201510351

24. Xu C, Arancon RAD, Labidi J, Luque R (2014) Lignin depolymerisation strategies: towards valuable chemicals and fuels. Chem Soc Rev 43:7485-7500. https://doi.org/10.1039/C4CS00235K

25. Zhang Z, Song J, Han B (2017) Catalytic transformation of lignocellulose into chemicals and fuel products in ionic liquids. Chem Rev 117:6834-6880. https://doi.org/10.1021/acs.chemrev.6b00457

26. Gillet S, Aguedo M, Petitjean L, Morais ARC, da Costa Lopes AM, Łukasik RM, Anastas PT (2017) Lignin transformations for high value applications: towards targeted modifications using green chemistry. Green Chem 19:4200-4233. https://doi.org/10.1039/C7GC01479A

27. Kozliak EI, Kubátová A, Artemyeva AA, Nagel E, Zhang C, Rajappagowda RB, Smirnova AL (2016) Thermal liquefaction of lignin to aromatics: efficiency, selectivity, and product analysis. ACS Sustain Chem Eng 4:5106-5122. https://doi.org/10.1021/ acssuschemeng.6b01046

28. Li S-H, Liu S, Colmenares JC, Xu Y-J (2016) A sustainable approach for lignin valorization by heterogeneous photocatalysis. Green Chem 18:594-607. https://doi.org/10.1039/C5GC02109J

29. Ma R, Guo M, Zhang X (2018) Recent advances in oxidative valorization of lignin. Catal Today 302:50-60. https://doi.org/10.1016/ j.cattod.2017.05.101

30. Otromke M, White RJ, Sauer J (2019) Hydrothermal base catalyzed depolymerization and conversion of technical lignin — an introductory review. Carbon Resour Convers 2:59-71. https://doi.org/10. 1016/j.crcon.2019.01.002

31. Sluiter A, Hames B, Ruiz R, et al (2012) Determination of structural carbohydrates and lignin in biomass

32. Crestini C, Argyropoulos DS (1997) Structural analysis of wheat straw lignin by quantitative 31P and 2D NMR spectroscopy. The occurrence of ester bonds and $\alpha-\mathrm{O}-4$ substructures. J Agric Food Chem 45:1212-1219

33. Granata A, Argyropoulos DS (1995) 2-Chloro-4,4,5,5-tetramethyl1,3,2-dioxaphospholane, a reagent for the accurate determination of the uncondensed and condensed phenolic moieties in lignins. J Agric Food Chem 43:1538-1544

34. Faix O (1992) Fourier transform infrared spectroscopy. In: Lin SY, Dence CW (eds) Methods in lignin chemistry, 1st ed. Springer Series in Wood Science, pp 83-109

35. Pu Y, Cao S, Ragauskas AJ (2011) Application of quantitative 31P NMR in biomass lignin and biofuel precursors characterization. Energy Environ Sci 4:3154. https://doi.org/10.1039/c1ee01201k

36. Guerra A, Norambuena M, Freer J, Argyropoulos DS (2008) Determination of arylglycerol- $\beta$-aryl ether linkages in enzymatic mild acidolysis lignins (EMAL): comparison of DFRC/31P NMR with thioacidolysis $\perp$. J Nat Prod 71:836-841. https://doi.org/10. $1021 / \mathrm{np} 800080 \mathrm{~s}$

37. Käldström M, Meine N, Farès C, Schüth F, Rinaldi R (2014) Deciphering 'water-soluble lignocellulose' obtained by mechanocatalysis: new insights into the chemical processes leading to deep depolymerization. Green Chem 16:3528-3538. https://doi. org/10.1039/C4GC00004H

38. Mansfield SD, Kim H, Lu F, Ralph J (2012) Whole plant cell wall characterization using solution-state 2D NMR. Nat Protoc 7:15791589. https://doi.org/10.1038/nprot.2012.064

39. Wen J-L, Sun S-L, Xue B-L, Sun R-C (2013) Recent advances in characterization of lignin polymer by solution-state nuclear magnetic resonance (NMR) methodology. Materials (Basel) 6:359-391. https://doi.org/10.3390/ma6010359

40. Ni Y, Hu Q (1995) Alcell@ lignin solubility in ethanol-water mixtures. J Appl Polym Sci 57:1441-1446. https://doi.org/10.1002/ app.1995.070571203

41. Cheng S, D'cruz I, Wang M, Leitch M, Xu C(C) (2010) Highly efficient liquefaction of woody biomass in hot-compressed alcohol -water co-solvents†. Energy Fuel 24:4659-4667. https://doi.org/ 10.1021/ef901218w

42. Ye Y, Zhang Y, Fan J, Chang J (2012) Novel method for production of phenolics by combining lignin extraction with lignin depolymerization in aqueous ethanol. Ind Eng Chem Res 51:103-110. https:// doi.org/10.1021/ie202118d

43. Ndou A (2003) Dimerisation of ethanol to butanol over solid-base catalysts. Appl Catal A Gen 251:337-345. https://doi.org/10.1016/ S0926-860X(03)00363-6

44. Ferrini P, Rinaldi R (2014) Catalytic biorefining of plant biomass to non-pyrolytic lignin bio-oil and carbohydrates through hydrogen transfer reactions. Angew Chemie - Int Ed 53:8634-8639. https:// doi.org/10.1002/anie.201403747

45. Gabriëls D, Hernández WY, Sels B, van der Voort P, Verberckmoes A (2015) Review of catalytic systems and thermodynamics for the Guerbet condensation reaction and challenges for biomass valorization. Catal Sci Technol 5:3876-3902. https://doi.org/10.1039/ C5CY00359H

46. Veibel S, Nielsen JI (1967) On the mechanism of the Guerbet reaction. Tetrahedron 23:1723-1733. https://doi.org/10.1016/S00404020(01)82571-0

47. Yang C, Meng ZY (1993) Bimolecular condensation of ethanol to 1-butanol catalyzed by alkali cation zeolites. J Catal 142:37-44. https://doi.org/10.1006/jcat.1993.1187

48. Chakar FS, Ragauskas AJ (2004) Review of current and future softwood kraft lignin process chemistry. Ind Crop Prod 20:131141. https://doi.org/10.1016/j.indcrop.2004.04.016

49. Joffres B, Lorentz C, Vidalie M, Laurenti D, Quoineaud AA, Charon N, Daudin A, Quignard A, Geantet C (2014) Catalytic hydroconversion of a wheat straw soda lignin: characterization of the products and the lignin residue. Appl Catal B Environ 145:167176. https://doi.org/10.1016/j.apcatb.2013.01.039

50. Lapierre C, Pollet B, Petit-Conil M, Toval G, Romero J, Pilate G, Leplé JC, Boerjan W, Ferret V, de Nadai V, Jouanin L (1999) Structural alterations of lignins in transgenic poplars with depressed cinnamyl alcohol dehydrogenase or caffeic acid $O$-methyltransferase activity have an opposite impact on the efficiency of industrial kraft pulping. Plant Physiol 119:153-164. https://doi.org/10.1104/ pp.119.1.153

51. Delmas G-H (2011) La Biolignine ${ }^{\mathrm{TM}}$ : Structure et Application à l'élaboration de résines époxy

52. Jongerius AL, Bruijnincx PCA, Weckhuysen BM (2013) Liquidphase reforming and hydrodeoxygenation as a two-step route to aromatics from lignin. Green Chem 15:3049-3056. https://doi. org $/ 10.1039 / \mathrm{C} 3 \mathrm{GC} 41150 \mathrm{H}$

Publisher's note Springer Nature remains neutral with regard to jurisdictional claims in published maps and institutional affiliations. 